\title{
Erkeklerde İş-Yaşam Dengesi Üzerine Bir Araştırma
}

DOI: 10.26466/opus.522715

*

Kezban Özçelik Kaynak*

* Dr, Dokuz Eylül Üniversitesi Rektörlüğ̈̈ İzmir/ Türkiye

E-Posta: kezban.kaynak@deu.edu.tr

ORCID: 0000-0002-1487-6033

** Dr. Öğr. Üyesi, Çankırı Karatekin Üniversitesi, İktisadi ve İdari Bilimler Fakültesi, Çalışma

Ekonomisi ve Endüstri İlişkiler Çankırı/ Türkiye

E-Posta: barisoz83@yahoo.com

ORCID: $\underline{0000-0001-7298-4641}$

$\ddot{O} z$

Çalışmanın amacı, erkek çalışanların iş-yaşam dengesine bakış açılarını incelemektedir. O yüzden anket uygulaması sadece erkek çalışanlara uygulanmıştır. Araştırmanın örneklemi Dokuz Eylül Üniversitesi Hastanesinde çalışan erkeklerden oluşmaktadır. Katılımcılar 657/4-a Memur, 657/4-b Sözleşmeli Personel ve 657/4-d Sürekli İşçilerden oluşmaktadır. Çalışmada veri toplama aracı olarak anket yöntemi kullanılmıştır. Kurumdan gerekli izin alındıktan sonra 115 anket değerlendirmeye alınmıştır. Anket iki bölümden oluşmaktadır. İlk bölüm demografik sorulardan meydana gelmiştir. Anketin ikinci bölümde ise, iş-yaşam dengesi ölçülmektedir. Ankette beşli Likert tipi derecelendirme ölçeği kullanılmıştır. Veriler IBM SPSS V23 ile analiz edilmiştir. İş-yaşam dengesi ölçeği alt boyutları ortalama değerlerinin çalışma sistemi ve çocuk sayısına göre karşılaştırılması tek yönlü varyans analizi ile, eşin çalışma durumuna göre karşılaştırma ise bağımsı örnekler t testi ile incelenmiştir. Kategorik veriler frekans ve yüzde olarak sunulurken nicel veriler ortalama \pm standart sapma olarak sunulmuştur. Araştırmada, eşin çalışma durumuna göre iş yaşam uyumu, kendine zaman ayırma ve yaşamın işten ibaret olması, ortalama değerleri arasında istatistiksel olarak fark olmadığı ortaya çıkmıştır. Çalışmada, yaşamı ihmal etme ortalama değerleri eşin çalışma durumuna göre farklılık göstermektedir.

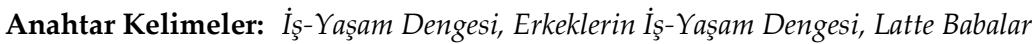




\title{
A Study on Work-Life Balance in Men
}

\begin{abstract}
The aim of the study is to examine the perspectives of male employees towards work-life balance. Therefore, the survey was applied only to male employees. The sample of the study consisted of men working in Dokuz Eylül Hospital. Participants consist of 657/4-a Civil Servants, 657/4-b Contracted Personnel and 657/4-d Continuous Workers. The questionnaire method was used as the data collection tool. After obtaining the necessary permission from the Authority, 115 questionnaires were taken into consideration. The questionnaire consists of two parts. The first part consisted of demographic questions. In the second part of the survey, the work-life balance is measured. A five-point Likert-type rating scale was used in the survey. Data were analyzed with IBM SPSS V23. The comparison of the mean values of the work-life balance scale sub-dimensions according to the number of the working system and the number of children were analyzed by one-way analysis of variance, and the comparison according to the working status of the spouse was examined by independent samples t-test. Categorical data are presented as frequency and percentage, while quantitative data are presented as mean \pm standard deviation. In the study, it was found that there was no statistically significant difference between the average values of the work-life according to the working status of the spouse, the time allocation of life and the fact that life was all about work. In the study, average values of life neglect differ according to the working status of the spouse.
\end{abstract}

Keywords: Work-Life Balance, Men's Work-Life Balance, Latte Dads 


\section{Giriş}

İnsanların günümüzde ihtiyaçlarını karşılamaları için çalışması gerekmektedir. Çalışma saatlerinin fazla olması çalışanların özel yaşamındaki sürelerinin azalmasına sebep olmuştur. Çalışan ebeveynler için çocukların bakımı ve onlara ayrılacak zaman önem kazanmıştır. Bu konularda daha çok kadınlar sorumluluk almaya başlamıştır ve bu nedenle de kadınlar iş dünyasından feragat eden kişiler arasında olmaktadır. Günümüzde özellikle babalar da çocuklarıyla vakit geçirmek için daha çok zamanlarının olmasını istemektedirler. İsveçli babalar buna iyi bir örnek oluşturmaktadır. İsveç'teki uygulamalar sayesinde babalar çocuklarıyla daha çok vakit geçirmektedirler. Hatta İsveçli babalara "latte baba" denilmektedir. Latte baba denilmesinin nedeni, İsveç'te kafelerde çocuklarıyla oturan babaların sıklıkla yer alamsıdır. İsveç'in ebeveyn izin süresinin çok olması sebebiyle babaların çocuklarının bakımını üstlenmesine izin vermektedir.

$\mathrm{Bu}$ çalışma, erkeklerin iş-yaşam dengesi konusuna yönelik beklentilerini ele almaktadır. Çalışmada, iş-yaşam dengesi kavramı ve erkeklerin iş-yaşam dengesi konusu incelenmektedir

\section{İş-Yaşam Dengesi}

İş-yaşam dengesi çalışanların bir yandan işteki sorumluluklarını, bir yandan da ailesi arasındaki uyumunu belirtmektedir. Çalışanlar hangi işte çalışırsa çalışsın, iş ve özel yaşamlarını dengelemeye çalışmaktadır. Çalışan için yaşamda işin önemli bir boyuta gelmesi, daha uzun çalışma saatleri, ekonomik zorluklar, aile içindeki sorumluluklar, iş ve aile talepleri arasındaki rekabeti daha da fazla önemli hale getirmektedir (Kapız, 2002, s.140). Çalışanların verimlilikleri ve motivasyonları da iş yaşam kalitesi açısından önemlidir. İş yaşamının zorlaşması, teknolojik gelişmeler ve küreselleşme ile gelen sosyo-ekonomik değişimler ile iş ve özel yaşam birbiriyle kesişmiş ve birbirlerinin alanlarını engellemeye başlamıştır (Akın ve diğerleri, 2017, s.114). İş-yaşam dengesi, bireyin işyaşam çatışmasını en az düzeyde yaşaması ve özel yaşamında kendisini daha mutlu hissetmesidir (Apaydın, 2011, s.64-65).

Sadece erkeklerin çalıştığı aileler yerini ailede hem kadının hem de erkeğin çalıştığ1 ailelere bırakmıştır. Kadının ve erkeğin iş ve aile 
yaşamında sahip oldukları sorumlulukları yerine getirme isteği denge kurulmasını zorunlu hale getirmiştir (Doğrul ve Tekeli, 2010, s.12). İş-yaşam dengesi şirketler için de önemlidir. Bir şirketin çalışanlarında iş-yaşam dengesi ile ilgili sorunları olanlarda; devamsızlık, isteksizlik gibi çalışanların performansını olumsuz etkileyen nedenler ortaya çıkmıştır (Korkmaz ve Erdoğan, 2014, s.553).

2018 yılında açıklanan OECD Better Life Index, araştırmasına göre en iyi iş-yaşam dengesine sahip ülkesi Hollanda olduğu belirlendi. En iyi işyaşam dengesine sahip 10 ülke aşağıdaki tablo 1'de yer verilmiştir.

Tablo 1: En İyi İş-Yaşam Dengesine Sahip 10 Ülkesi

\begin{tabular}{lll}
\hline & Ülke & Skor \\
\hline 1 & Hollanda & 9.3 \\
2 & Danimarka & 9.0 \\
3 & Fransa & 8.9 \\
4 & İspanya & 8.8 \\
5 & Belçika & 8.6 \\
6 & Norveç & 8.5 \\
7 & İsveç & 8.3 \\
8 & Almanya & 8.3 \\
9 & Rusya & 8.1 \\
10 & İrlanda & 7.9 \\
\hline
\end{tabular}

Kaynak: OECD, 2018

İş-yaşam dengesi için Hollanda, muhtemel 10 üzerinden 9,3 ile skor alırken, ikinci sırada ise Danimarka yer almaktadır. Araştırmada ölçülen 35 OECD ülkesi arasında, Türkiye'nin iş-yaşam dengesi en kötü ülke olarak değerlendirilirken, Meksika ise yalnızca 0.8 ile Türkiye'ye çok yakın bir skor almıştır (Smith, 2018). İş-yaşam dengesinin önemli bir yönü, bir kişinin işte geçirdiği zaman miktarıdır. Kanıtlar, uzun çalışma saatlerinin kişisel sağlığı bozabileceğini, güvenliği tehlikeye sokabileceğini ve stresi artırabileceğini öne sürmektedir. Bununla birlikte, Türkiye'de çalışanların yaklaşık \% 34'ü, çok uzun saatler çalışmaktadır. OECD ülkeleri arasında en fazla çalışma süresine sahip olan ülke Türkiye'dir (OECD, 2018). Hollandalı çalışanların ise sadece \% 0,5'i düzenli olarak çok uzun saatler çalışmaktadır. Genel olarak, haftada ortalama 30.3 saat çalışmaktadırlar. AB ortalaması ise haftada ortalama 40.3 saattir. 
Hollandalılar günde yaklaşık 16 saat yemek yemeye, uyumaya ve boş zaman uğraşlarına adamaktadırlar (McKenna, 2018).

\section{Erkeklerin İş-Yaşam Dengesi}

İsveç, dünyadaki en ilerici sosyal politikalardan bazılarına sahiptir ve 1970'lerden bu yana İsveç Hükümeti, her iki ebeveynin de çocuklarını büyütmek için ücretli izin kullanmalarını mümkün kılmıştır (SBS, 2014). İsveçli babalar çocukları ile diğer birçok ülke babalarına göre daha çok vakit geçirmektedirler. Sahip oldukları her çocuk için, İsveçli ebeveynler yasal olarak işten 480 gün izin hakkına sahiptir. Bu izin sırasında, ilk 390 gün içinde maaşlarının yüzde 80 'ini ve daha sonra ebeveyn başına günde yaklaşık 20 ABD Dolarına eşdeğer bir ücret almaktadırlar. 480 günün üç ayı babalar tarafından alınmaktadır. İsveçli babalar çocukları ile daha çok vakit geçirmektedirler.

Tablo 2. Ülkelerin Ücretli Babalık ve Toplam Ebeveyn İzinleri

\begin{tabular}{|c|c|c|c|}
\hline \multirow{2}{*}{ Ülkeler } & \multirow{2}{*}{$\begin{array}{l}\text { Ücretli Babalık } \\
\text { İzinleri }\end{array}$} & Devlet/Özel & \multirow[t]{2}{*}{ Toplam Ebeveyn İzinleri } \\
\hline & & $\begin{array}{l}\text { Sektör Des- } \\
\text { teği }\end{array}$ & \\
\hline Norveç & 14 Hafta & Var & $\begin{array}{l}59 \text { Hafta (14 hafta baba tarafın- } \\
\text { dan zorunlu kullanılması gere- } \\
\text { ken ücretli izin) }\end{array}$ \\
\hline Danimarka & 14 hafta & Var & $\begin{array}{l}52 \text { hafta ( } 2 \text { hafta baba tarafın- } \\
\text { dan zorunlu kullanılması gere- } \\
\text { ken ücretli izin) }\end{array}$ \\
\hline Finlandiya & 9 hafta & Var & $\begin{array}{l}25 \text { hafta (9 hafta baba tarafın- } \\
\text { dan zorunlu kullanılması gere- } \\
\text { ken ücretli izin) }\end{array}$ \\
\hline İzlanda & 12 hafta & Var & 12 hafta \\
\hline Almanya & Yok & Var & 52 hafta \\
\hline İngiltere & 2 hafta & Yok & 13 hafta (ücretsiz izin) \\
\hline Türkiye & $\begin{array}{l}1 \text { hafta (10 gün } \\
\text { memur) }\end{array}$ & Yok & 24 ay (ücretsiz izin) \\
\hline
\end{tabular}

Kaynak: Kavas, 2018, s.4.

2017 yılında İsveçli babalar ülke çapındaki çiftlere ayrılan toplam iznin yüzde 27'sinden fazlasını almıştır. Stockholm bölgesi artık "latte babaları" 
ile doludur. $\mathrm{Bu}$ tip babalar bebeklerini askıda taşıyan veya küçük çocuklarıyla takılanlara denilmektedir. İsveç hükümetine göre, babaları ile daha kaliteli zaman geçiren çocuklara sosyal faydası bulunmaktadır. Aynı zamanda kadınların kariyerlerini takip etmelerini ve işgücünün daha aktif bir üyesi olmalarını da sağlamaktadır (Smith ve Banic, 2018). Ülkelerin ücretli babalık ve toplam ebeveyn izinleri tablo 2'de yer verilmiştir.

İşletmelerde kadın çalışanların sayısının artmasıyla birlikte işletmelerin rekabet güçlerini artıracaktır. İşletmeler için kadın çalışanlar itici bir güç oluşturmakta ve değişen rekabette işletmelerin kadın çalışanlara önem vermeleri gerekmektedir (Kaplan, 2018, s.34). İsveç, İzlanda gibi ülkelerin deneyimlerinin gösterdiği gibi, anneleri işgücünde tutmanın sırrı, onlara daha fazla zaman ayırmakta değil, daha çok babaları evde bırakmada yatmaktadır. 10 İsveçli babanın dokuzu, her biri ortalama üç ila dört ay süreyle izin almakta ve bu izin toplam izin süresinin dörtte birini oluşturarak annenin işe dönüşünü yumuşatmaktadır. Bunun işe yaramasının bir nedeni, İsveç'in nispeten kısa bir izin süresi için cömert haklar ödemesidir. Kadınları işgücünün dışında uzun bir süre geçirmeye teşvik etmek yerine, işe geri dönmelerini sağlamak gerekmektedir. Baba izninin eklenmesi, bir bebeğin ailesiyle geçirebileceği fazladan zaman eklemektedir (Guilford, 2014). Türkiye'de ise, babalık ve ebeveyn izinlerine ilişkin düzenlemeler, kadın istihdamının esnekleştirilmesine ve güvensizleştirilmesine sebebiyet vermektedir. Bu yüzden sadece kadınların doğum izni, emzirme izni, kısmi çalışma gibi bireysel düzenlemelerin değil, babalara verilen ebeveyn iznini de içinde bulunduran, bakım sorumluluklarının çözümünü de kapsayan genel politikaların düzenlenmesini sağlamak gerekmektedir (Kavas, 2018: 9).

Çalışmalar, iş esnekliğine para ve promosyonlardan daha fazla değer verdiğini göstermektedir. Daha iyi bir iş-yaşam dengesi bulmak için yeni bir işe, hatta yeni bir ülkeye taşınmaya isteklidirler. Esnek iş düzenlemelerinin de iş için verimli olduğu kanıtlanmıştır. Esnek çalışanlar daha sağlıklı, daha mutlu ve daha üretken olma eğilimindedirler (Raymond, 2016). Boston College's İş ve Aile Merkezi tarafından yapılan bir araştırmaya göre, üç tip çalışan baba vardır. Babaları bakıcılık konusunda baskın davranış özelliklerine göre sorgulayarak tanımlamakta ve babalık tipleri eşitlikçi, geleneksel ve çatışmalı babalar olarak karşımıza 
çıkmaktadır (Harrington ve diğerleri, 2017, s.6). Bu üç tür babalık tipi aşağıdaki gibidir (Behson, 2016):

- Eşitlikçi Babalar: Bakıcılık işlerinin eşit yapılması gerektiğini söyleyen babalar, işlerin eşit paylaşılması ve bu işlerin birlikte yapması gerektiğini savunurlar.

- Geleneksel Babalar: Bakıcılık yapmak istemeyen babalar, eşlerinin daha fazlasını yapması gerektiğini söylemektedirler.

- Çatışmalı Babalar: Bakıcılık işlerinin eşit şekilde paylaşılması gerektiğini ancak bunun gerçekleşmesi için bir yol bulamadıklarını söyleyen babalardan oluşmaktadır.

İngiltere'de 2017 yılında "Çalışma Aileleri" tarafından yapılan çalışmada, bugünün babalarının Babalar Günü'nde ihtiyaç duydukları şeyin, işte daha fazla esnekliğin olması gerektiği düşüncesinin çıkmasıdır. Ankete 300'den fazla baba katılmıştır. Babaların üçte birinden fazlası (\%36) mevcut çalışma düzenlemelerinin çocuk bakımı sorumluluklarını yerine getirmelerini desteklemediğini söylemektedir. On babadan dördü (\%40) çocuklarının yetiştirilmesinde daha aktif bir rol oynamak istemektedir. Beş babadan biri (\%18) çocuk bakımı sorumluluklarını eşleriyle daha eşit paylaşmak istemektedir (Working Families, 2017). Günümüzde çalışma süresinin fazlalığı iş-yaşam dengesini daha önemli hale getirmektedir. Erkeklerin özellikle son yıllarda aileleriyle daha fazla vakit geçirme isteği birçok ülkede sıklıkla gündeme gelmektedir. Babalar, çocuklarının yetiştirilmesinde daha aktif rol almak istemektedirler.

\section{Araştırma Yöntemi}

Araştırma, kavramsal ve uygulamalı bir çalışmadır. Kavramsal kısım, literatürden faydalanarak hazırlanmıştır. Uygulama kısmında ise, veri toplama yöntemlerinden anket tekniği kullanılmıştır. Bu çalışmada uygulanan anket ile ilgili araştırmanın evreni, örneklemi ve yöntemi aşağıda verilmiştir.

\section{Araştırmanın Evren ve Örneklemi}

Dünyada erkeklerin iş-yaşam dengesi konusu özellikle de İsveç'te ortaya çıkan "latte baba" tanımıyla birlikte, babaların aileleri ve çocuklarıyla 
daha çok vakit geçirme isteği ve diğer ülkelerdeki erkeklere iyi örnek olması durumu, konuyu daha fazla gündeme getirmiştir. Bu çalışmada, erkek çalışanların iş-yaşam dengesi uygulamalarına ilişkin düşünceleri incelenmiş ve uygulanan anket sonuçlarına ilişkin bulgular ele alınmıştır.

Çalışmanın amacl, erkek çalışanların iş-yaşam dengesine bakış açılarını incelemektedir. Anket uygulaması yalnızca erkek çalışanlara uygulanmıştır. Araştırmanın örneklemi Dokuz Eylül Üniversitesi Hastanesinde çalışan erkeklerden oluşmaktadır. Katılımcılar 657/4-a Memur, 657/4-b Sözleşmeli Personel ve 657/4-d Sürekli İşçilerden oluşmaktadır.

Çalışmada veri toplama aracı olarak anket yöntemi kullanılmıştır. Kurumdan gerekli izin alındıktan sonra 446 anket formu dağıtılmış olup; 115 katılım ile araştırma tamamlanmıştır. Böylece erkek çalışanların yaklaşık 4'te 1'i örneklemimize dâhil olmuştur.

\section{Veri Toplama Yöntemi ve Aracı}

Anket iki bölümden oluşmaktadır. İlk bölüm demografik sorulardan meydana gelmiştir. Anketin ikinci bölümde ise, İş-yaşam dengesi ölçülmektedir. Bunun için de Apaydın (2011) tarafından hazırlanan iş-yaşam dengesi ölçeği kullanılmıştır. Ankette beşli Likert tipi derecelendirme ölçeği kullanılmıştır. Derecelendirmeler, (1) hiç katılmıyorum, (2) çok az katılıyorum, (3) biraz katılıyorum, (4) büyük ölçüde katılıyorum, (5) tam katılıyorum olarak sınıflandırılmıştır.

\section{İstatistiksel Yöntem}

Veriler IBM SPSS V23 ile analiz edilmiştir. İş-yaşam dengesi ölçeği alt boyutları ortalama değerlerinin çalışma sistemi ve çocuk sayısına göre karşılaştırılması tek yönlü varyans analizi ile, eşin çalışma durumuna göre karşılaştırma ise bağımsız örnekler $t$ testi ile incelenmiştir. Kategorik veriler frekans ve yüzde olarak sunulurken nicel veriler ortalama \pm standart sapma olarak sunulmuştur. Önem düzeyi $p<0,05$ olarak alınmıştır. 


\section{Katılımcıların Demografik Özellikleri}

Kişisel bilgilerinin frekans ve yüzde dağılımı tablo 3'te ele alınmaktadır. Araştırmaya katılanların \%2,6'sı 18-25 yaş aralığında iken \%11,3'ü 26-30, $\% 16,5^{\prime}$ i 31-35, \%23,5'i 36-40 ve \%46,1'i de 41 ve üzeri yaş aralığındadır.

Tablo 3. Katılımcıların Demografik Özelliklerin Frekans ve Yüzdelik Dilimleri

\begin{tabular}{lcc}
\hline Yaş & $\mathrm{N}$ & $\%$ \\
\hline $18-25$ & 3 & 2,6 \\
$26-30$ & 13 & 11,3 \\
$31-35$ & 19 & 16,5 \\
$36-40$ & 27 & 23,5 \\
41 ve üzeri & 53 & 46,1 \\
\hline Medeni Durum & & \\
\hline Evli & 94 & 81,7 \\
Bekar & 21 & 18,3 \\
\hline Eğitim Durumunuz & & \\
\hline İköğretim & 5 & 4,3 \\
Ortaöğretim & 16 & 13,9 \\
Lise & 56 & 48,7 \\
Üniversite ve üzeri & 38 & 33,0 \\
\hline İstihdam türü & & \\
\hline 657/4-a Memur & 54 & 47,0 \\
657/4-b Sözleşmeli Personel & 5 & 4,3 \\
657/4-d Sürekli İşçi & 56 & 48,7 \\
Hizmet Sinıfı & & \\
İdari Hizmetler & 44 & 38,3 \\
Sağllk Hizmetleri & 32 & 27,8 \\
Teknik Hizmetler & 14 & 12,2 \\
Yardımcı Hizmetler & 25 & 21,7 \\
\hline Çalışma Sistemi & & \\
\hline Sürekli Gündüz & 54 & 47,0 \\
Sürekli Gece & 6 & 5,2 \\
Nöbet & 55 & 47,8 \\
\hline Çalışma Süresi & & \\
\hline 5 Yıl ve altı & 25 & 21,7 \\
6-10 Yıl & 25 & 21,7 \\
11-20 Yıl & 46 & 40,0 \\
21 Y1l ve Üzeri & 19 & 16,5 \\
\hline & & \\
\hline & & \\
\hline
\end{tabular}

Evli olanların oranı \%81,7 iken bekar olanların oranı \%18,3'tür. Katılımclların eğitim düzeyi incelendiğinde $\% 48,7^{\prime}$ si lise mezunu iken \%33'ü üniversite ve üzeri eğitime sahiptir. 657/4-d olarak istihdam olanların 
oranı \%48,7 iken 657/4-a Memur olarak istihdam edilenlerin oranı $\% 47$ 'dir. Görüssme yapılan personelin \%38,3'ü idari hizmetler, $\% 27,8^{\prime}$ i sağlık hizmetleri, \%21,7'si yardımcı hizmetler ve \%12,2'si de teknik hizmetlerde görev yapmaktadır. Çalışma sistemi açısından sürekli gündüz çalışanların oranı \%47 iken nöbet usulü çalışanların oranı $\% 47,8$ ve sürekli gece çalışanların oranı da \%5,2'dir. İş yerinde çalışma süresi 5 yıl ve altı olanların oranı \%21,7, 6-10 yıl arası olanların oranı \%21,7, 11-20 yıl arası olanların oranı $\% 40$ ve 21 yıl ve üzeri olanların oranı $\% 16,5^{\prime}$ tir.

Tablo 4'te ise ankete katılan erkek çalışanların eşleri hakkında bilgilere yer verilmiştir.

Tablo 4. Ankete Katılan Katılımcıların Eş ve Çocuk Bilgilerinin Frekans ve Yüzdelik Dilimleri

\begin{tabular}{lcc}
\hline & $\mathrm{N}$ & $\%$ \\
\hline Eşin ücretli çalışma durumu & & \\
\hline Tam zamanlı & 51 & 54,3 \\
Yarı zamanlı & 4 & 4,3 \\
Çalışmıyor & 38 & 40,4 \\
Emekli & 1 & 1,1 \\
Eşin eğitim durumu & & \\
\hline İlköğretim & 23 & 24,5 \\
Ortaöğretim & 14 & 14,9 \\
Lise & 30 & 31,9 \\
Üniversite ve üzeri & 27 & 28,8 \\
Sahip olunan çocuk sayısı & & \\
\hline Yok & 15 & 14,2 \\
1 & 32 & 30,2 \\
2 & 47 & 44,3 \\
3 ve üstü & 12 & 11,3 \\
\hline
\end{tabular}

Eşi tam zamanlı çalışanların oranı \%54,3 iken eşi çalışmayanların oranı $\% 40,4^{\prime}$ tür. Eşlerin eğitim durumu incelendiğinde \%31,9 ile lise mezunları ilk sırada yer alırken \%28,8'i üniversite ve üzeri ve $\% 24,5$ 'i de ilköğretim mezunudur. Katılımcların \%14,2'sinin çocuğu yoktur ve iki çocuk sahibi olanların oranı da \%44,3'tür. Eşin çalışma durumunu çalışanlar (tam zamanl1+yarı zamanlı) \%58,6 (55 kişi) ve çalışmayanlar (çalışmıyor + emekli) \%41,5 (39 kişi) olarak analize dahil edilmiştir. 


\section{Tanımlayıcı İstatistikler}

20 maddeden oluşan iş-yaşam denge ölçeğine ait toplam 11 madde olumsuz maddeler olduğundan ters çevirme işlemi yapılmıştır. Ters çevirme işleminin artından her bir boyutta yer alan maddeler toplanarak madde sayısına bölünmüş ve ilgili boyutun ortalama değeri elde edilmiştir.

Tablo 5. İş-Yaşam Dengesi Ölçeği

\begin{tabular}{lcccc}
\hline & N & Madde Sa- & Ortalama & S. Sapma \\
\hline İş-Yaşam Uyumu & 115 & 6 & 3,393 & 0,832 \\
Yaşamı İhmal Etme & 115 & 6 & 3,296 & 0,639 \\
Kendine Zaman Ayırma & 115 & 4 & 3,480 & 0,857 \\
Yaşamın İşten İbaret Olması & 115 & 4 & 3,441 & 0,912 \\
\hline
\end{tabular}

İş yaşam uyumu toplam 6 maddeden oluşmaktadır. Boyut ortalama değeri 3,393 ve standart sapma değeri de 0,832 olarak elde edilmiştir. Yaşamı ihmal etme boyutunda da toplam 6 madde yer almaktadır. Ortalama değer 3,296 ve standart sapma değeri 0,639 olarak elde edilmiştir. Kendine zaman ayırma boyutunda ise toplamda 4 madde yer almaktadır ve ortalama değeri 3,480 iken standart sapma değeri 0,857 olarak elde edilmiştir. Yaşamın işten ibaret olması boyutunda da toplam 4 madde yer almaktadır ve ortalama değer 3,441, standart sapma değeri de 0,912 olarak elde edilmiştir.

Tablo 6. Çocuk Sayısına Göre Ortalama Değerlerin Karşılaştırılması

\begin{tabular}{lcccc}
\hline & İş Yaşam Uyumu & $\begin{array}{c}\text { Yaşami İhmal } \\
\text { Etme }\end{array}$ & $\begin{array}{c}\text { Kendine Zaman } \\
\text { Ayırma }\end{array}$ & $\begin{array}{c}\text { Yaşamın İşten } \\
\text { İbaret Olmas }\end{array}$ \\
\hline Yok & $3,556 \pm 0,971$ & $3,440 \pm 0,647$ & $3,317 \pm 0,894$ & $3,333 \pm 0,843$ \\
1 & $3,510 \pm 0,820$ & $3,388 \pm 0,711$ & $3,391 \pm 0,933$ & $3,492 \pm 0,983$ \\
2 & $3,270 \pm 0,818$ & $3,217 \pm 0,590$ & $3,495 \pm 0,888$ & $3,473 \pm 0,843$ \\
3 & $3,317 \pm 0,678$ & $3,200 \pm 0,680$ & $3,650 \pm 0,615$ & $3,450 \pm 0,911$ \\
4 ve üstü & $3,917 \pm 1,532$ & $3,600 \pm 0,283$ & $4,00 \pm 0,707$ & $4,125 \pm 1,237$ \\
\hline \multicolumn{1}{c}{ F } & 0,764 & 0,689 & 0,471 & 0,359 \\
\multicolumn{1}{c}{ p } & 0,551 & 0,601 & 0,757 & 0,837 \\
\hline
\end{tabular}

${ }^{*}$ Tek yönlü varyans analizi 
Çocuk sayısına göre ortalamaların karşılaştırılmasında ortalama değerler arasında fark olup olmadığı incelendiğinde iş-yaşam uyumu, yaşamı ihmal etme, kendine zaman ayırma ve yaşamın işten ibaret olması ortalama değerleri arasında istatistiksel fark yoktur.

Tablo 7. Eşin Çalışma Durumuna Göre Karşılaştırmalar

\begin{tabular}{lcccc}
\hline & Çalışıyor & Çalışmıyor & t & p \\
\hline İş-Yaşam Uyumu & $3,530 \pm 0,870$ & $3,261 \pm 0,772$ & 1,550 & 0,124 \\
Yaşamı İhmal Etme & $3,418 \pm 0,613$ & $3,144 \pm 0,691$ & 2,030 & 0,045 \\
Kendine Zaman Ayırma & $3,505 \pm 0,889$ & $3,385 \pm 0,896$ & 0,642 & 0,522 \\
Yaşamın İşten İbaret Olması & $3,555 \pm 0,918$ & $3,423 \pm 0,918$ & 0,684 & 0,495 \\
\hline
\end{tabular}

*Bă̆ımsız örnekler $t$ testi

Eşin çalışma durumuna göre iş yaşam uyumu ( $\mathrm{p}=0,124)$, kendine zaman ayırma $(p=0,522)$ ve yaşamın işten ibaret olması $(p=0,495)$ ortalama değerleri arasında istatistiksel olarak fark yoktur. Yaşamı ihmal etme ortalama değerleri eşin çalışma durumuna göre farklılık göstermektedir $(\mathrm{p}=0,045)$. Eşi çalışanlarda ortalama değer 3,418 iken çalışmayanlarda 3,144 olarak elde edilmiştir. Buna göre, eşi çalışanların yaşamı daha fazla ihmal ettiği sonucu ortaya çıkmaktadır.

Tablo 8. Çalışma Sistemine Göre Ortalama Değerlerin Karşılaştırılması

\begin{tabular}{lcccc}
\hline & $\begin{array}{l}\text { İş Yaşam } \\
\text { Uyumu }\end{array}$ & $\begin{array}{l}\text { Yaşamı İhmal } \\
\text { Etme }\end{array}$ & $\begin{array}{l}\text { Kendine Zaman } \\
\text { Ayırma }\end{array}$ & $\begin{array}{l}\text { Yaşamin İşten İbaret } \\
\text { Olması }\end{array}$ \\
\hline $\begin{array}{l}\text { Sürekli } \\
\text { Gündüz }\end{array}$ & $3,500 \pm 0,852$ & $3,174 \pm 0,591$ & $3,588 \pm 0,850$ & $3,560 \pm 0,910$ \\
Sürekli & & & & \\
Gece & $3,917 \pm 0,603$ & $3,467 \pm 0,484$ & $3,958 \pm 0,797$ & $3,750 \pm 0,707$ \\
Nöbet & $3,230 \pm 0,803$ & $3,396 \pm 0,686$ & $3,323 \pm 0,849$ & $3,291 \pm 0,923$ \\
\hline \multicolumn{1}{c}{ F } & 2,771 & 1,904 & 2,342 & 1,564 \\
p & 0,067 & 0,154 & 0,101 & 0,214 \\
\hline
\end{tabular}

${ }^{*}$ Tek yönlü varyans analizi

Çalışma sistemine göre ortalama değerler arasında istatistiksel olarak fark yoktur. Sürekli gece çalışanların, sürekli gündüz çalışanlardan daha fazla yaşamı ihmal ettiği görülmektedir. Bununla birlikte, sürekli gece 
çalışanlar, sürekli gündüz çalışanlara göre yaşamı daha fazla işten ibaret olarak görmektedirler.

\section{Sonuç}

Bu çalışmada, erkek çalışanların iş-yaşam dengesi uygulamalarına ilişkin düşünceleri incelenmiş ve uygulanan anket sonuçlarına ilişkin bulgular yer almaktadır. Çalışmanın amacı, erkek çalışanların iş-yaşam dengesine bakış açılarını incelemektedir. Bu nedenle, anket uygulaması yalnızca erkek çalışanlara uygulanmıştır. Dokuz Eylül Üniversitesi Hastanesinde çalışan erkeklerden oluşan katılımcların eğitim düzeyi incelendiğinde ilköğretim mezunu \% 4,3'nü, ortaöğretim mezunu \% 13,9'unu, lise mezunu \% 48,7'sini, \%33'ü ise üniversite ve üzeri eğitime sahiptir. Görüldüğü üzere katılımcıların büyük bir çoğunluğu lise, üniversite ve üzeri mezunudur.

Katılımcıların eşlerinin çalışma durumuna göre, tam zamanlı olarak $\% 54,3$ 'ünü, yarı zamanlı \% 4,3'ünü, emekli \% 1,1'ini ve çalışmayanlar ise \%40,4'ünü oluşturmaktadır. Çalışmada, eşin çalışma durumuna göre iş yaşam uyumu, kendine zaman ayırma ve yaşamın işten ibaret olması ortalama değerleri arasında istatistiksel olarak fark olmadığ çalışmada ortaya çıkmıştır.

Çalışmada, yaşamı ihmal etme ortalama değerleri eşin çalışma durumuna göre farklılık göstermektedir. Eşi çalışanlarda ortalama değer 3,418 iken çalışmayanlarda 3,144 olarak elde edilmiştir. Buna göre, eşi çalışanların yaşamı daha fazla ihmal ettiği sonucu ortaya çıkmaktadır. Sürekli gece çalışanların, sürekli gündüz çalışanlardan daha fazla yaşamı ihmal ettiği araştırmada görülmektedir. Bununla birlikte, sürekli gece çalışanlar, sürekli gündüz çalışanlara göre yaşamı daha fazla işten ibaret olarak görmektedirler. Çocuk sayısına göre ortalama değerlerin karşılaştırılmasında iş-yaşam uyumu, yaşamı ihmal etme, kendine zaman ayırma ve yaşamın işten ibaret olması ortalama değerleri arasında istatistiksel fark olmadığı ortaya çıkmıştır.

Günümüzde kadınların çalışma hayatında olması ebeveynlerin sorumluluklarını bölüşmesine ve iş-özel yaşam dengesine önem verilmesi konusunu gündeme getirmiştir. İsveçli babalar çocukları ile diğer birçok ülke babalarına göre daha çok vakit geçirmektedirler. İsveç, İzlanda gibi 
ülkelerin deneyimlerinin gösterdiği gibi, anneleri işgücünde tutmanın sırrı, onlara daha fazla zaman ayırmakta değil, daha çok babaları evde bırakmada yatmaktadır (Guilford, 2014). Bu sayede kadınlar işgücünün içerisinde kalmış olacaklardır. Türkiye'de ise, babalık izni sadece 10 gündür. Türkiye'de çocuk bakımı konusunda kadınlar sorumluluk almaktadır.Oysa ki, Norveç ve Danimarka' da ücretli babalık izinleri 14 haftadır. 2018 yılında açıklanan OECD Better Life Index, araştırmasına göre en iyi iş-yaşam dengesine sahip ülke Hollanda olduğu belirlenmiştir. OECD ülkeleri arasında en kötü iş-yaşam dengesine sahip ülkeler, Türkiye ve Meksika olduğu ortaya çıkmıştır. Konuya erkekler açısından baktığımızda, erkeklerin özellikle son yıllarda aileleriyle daha fazla vakit geçirme isteği birçok ülkede sıklıkla gündeme gelmektedir. Babalar, çocuklarının yetiştirilmesinde daha aktif rol almak istemektedirler. 


\title{
EXTENDED ABSTRACT
}

\section{A Study on Work-Life Balance in Men}

\author{
Kezban Özçelik Kaynak - Barış Öztuna \\ Ege University - Çankırı Karatekin University
}

Work-life balance indicates the responsibilities of the employees on the one hand and the harmony between the family. Employees try to balance their work and private lives no matter what job they work for. For the employee, the important aspect of life in work, longer working hours, economic difficulties, responsibilities in the family, makes the competition between work and family demands even more important (Kapiz, 2002, p.140). Employees' productivity and motivation are important in terms of quality of work life. The difficulties of business life, technological developments and socio-economic changes with globalization and business and private life intersect each other and began to block each other's fields (Akın et al., 2017, p.114). Work-life balance is the individual living in a minimum level of work-life conflict and feeling happier in his private life (Apaydin, 2011, p.64-65).

Only the families where the men work have been replaced by the families in which both women and men work. The desire of women and men to fulfill their responsibilities in work and family life has made it necessary to establish a balance (Doğrul and Tekeli, 2010, p.12). Work-life balance is also important for companies. In those who have problems with work-life balance in a company's employees; reasons such as absenteeism, unwillingness and negatively affecting the performance of employees (Korkmaz and Erdogan, 2014, p.553).

People need to work today to meet their needs. The high number of working hours has led to a decrease in the personal lives of employees. The care of children for working parents and the time to devote to them have gained importance. Rather, women have started to take responsibility for these issues, and therefore women are among those who renounce the business world. Nowadays, especially fathers want to have more time to spend time with their children. Swedish fathers are a good example of 
this. Thanks to the practices in Sweden, fathers spend more time with their children. Even Swedish fathers are called "latte father".

This study examines men's expectations for work-life balance. In this study, the concept of work-life balance and the work-life balance of men are examined. The aim of the study is to examine the perspectives of male employees towards work-life balance. The survey was therefore only applied to male employees. The sample of the study consisted of men working in

Dokuz Eylül University Hospital. The questionnaire method was used as the data collection tool. After obtaining the necessary permission from the Authority, 446 questionnaires were distributed; Research was completed with 115 participants. Thus, approximately 4 of the male employees were included in our sample. The questionnaire consists of two parts. The first part consisted of demographic questions. In the second part of the survey, the work-life balance is measured. A five-point Likert-type rating scale was used in the survey. The ratings are classified as (1) strongly disagree, (2) little agree, (3) slightly agree, (4) largely agree, (5) fully agree. Data were analyzed with IBM SPSS V23. The comparison of the mean values of the work-life balance scale sub-dimensions according to the number of the working system and the number of children were analyzed by one-way analysis of variance, and the comparison according to the working status of the spouse was examined by independent samples t-test. Categorical data are presented as frequency and percentage, while quantitative data are presented as mean \pm standard deviation. The significance level was taken as $\mathrm{p}<0.05$.

According to the questionnaire survey, 115 of the participants were primary school graduates, $4.3 \%$ were secondary school graduates, $13.9 \%$ were high school graduates, $48.7 \%$ were university graduates, and $33 \%$ were university graduates. As it is seen, a great majority of the participants are graduates of high school, university and above.

According to the working status of the spouses of the participants, $54.3 \%$ of the full-time, part-time, $4.3 \%$, retiree $1.1 \%$ and non-workers constitute $40.4 \%$. In the study, it was found that there was no statistically significant difference between the mean values of work life adaptation, time separation and life consistency. 
In the study, mean values of life neglect differ according to the working status of the spouse. The average value of the employee in the spouse was 3,418 and in the ones who did not work was 3,144. There was no statistically significant difference between the mean values of the children according to the number of children in terms of work-life harmony, neglecting life, taking time out of themselves, and the average life.

\section{Kaynakça / References}

Akın, A., Ulukök, E., Arar, T. (2017). İş-yaşam dengesi: Türkiye'de yapılan çalışmalara yönelik teorik bir inceleme. AKÜ İ̈BF Dergisi, 19(1) 113-124.

Apaydın, Ç. (2011). Öğretim üyelerinin işe bağımlılık düzeyi ile iş-yaşam dengesi ve iş-aile yaşam dengesi arasındaki ilişki. Yayınlanmamış Doktora Tezi, Ankara Üniversitesi Eğitim Bilimleri Enstitüsü, Ankara.

Behson, S. (2016). 12 work-life balance tips from a working dad. https://www.success.com/12-work-life-balance-tips-from-a-working-dad/ adresinden 13.11.2018 tarihinde erişildi.

Doğrul, Ş., B., Tekeli, S. (2010). İş-yaşam dengesinin sağlanmasında esnek çalışma. Sosyal ve Beşeri Bilimler Dergisi, 2(2), 11-17.

Guilford, G. (2014). The economic case for paternity leave. https://qz.com/266841/economic-case-for-paternity-leave/ adresinden 10.09..2018 tarihinde erişildi.

Harrington, B., Fraone, S., J., Lee, J. (2017). The new dad the career-care giving conflict. Boston: Boston College Center for Work \& Family

Kapız, Özen, S. (2002). İş-aile yaşamı dengesi ve dengeye yönelik yeni bir yaklaşım: Sınır teorisi. Dokuz Eylül Üniversitesi Sosyal Bilimler Enstitüsü Dergisi, 4(3), 139-153.

Kaplan, M. (2018). Kadın çalışanların psikolojik sermayelerinin iş-yaşam dengesi üzerindeki etkisi: Tarihi işhanlarında bir araştırma. Balkan and Near Eastern Journal of Social Sciences, 4(3), 29-36.

Kavas, A. (2018). Türkiye'de babalar çocuk bakamıyor Türkiye ekonomi politikaları araştırma vakfı (TEPAV) Değerlendirme Notu. https://www.tepav.org.tr/upload/files/15330375176.Turkiye__de_Babalar_Cocuk_Bakamiyor.pdf adresinden 10.11.2018 tarihinde erişildi. 
Korkmaz, O., Erdoğan, E. (2014). İş yaşam dengesinin örgütsel bağlllık ve çalışan memnuniyetine etkisi. Ege Akademik Bakış, 14(4), 541-557.

McKenna, J. (2018). This is why dutch teenagers are among the happiest in the world. https://www.weforum.org/agenda/2018/06/this-is-why-dutchteenagers-are-among-the-happiest-in-the-world adresinden 20.11.2018 tarihinde erişildi.

OECD (2018). OECD better life index work-life balance. http://www.oecdbetterlifeindex.org/topics/work-life-balance/ adresinden 13.12.2018 tarihinde erişildi.

Raymond, C. (2016). Dads struggle with work-life balance, too. https://www.success.com/dads-struggle-with-work-life-balance-too/ adresinden 07.08.2018 tarihinde erişildi.

SBS (2014). Meet the 'Latte pappas': The Swedish men who stay home to look after the children.https://www.sbs.com.au/news/thefeed/story/meet-latte-pappas-swedish-men-who-stay-home-look-afterchildren adresinden 05.06.2018 tarihinde erişildi.

Smith, A., Banic, V. (2018). An American dad in Sweden now has plenty of family time. https://www.nbcnews.com/news/world/americandad-sweden-now-has-plenty-family-time-n851866 adresinden 14.12.2018 tarihinde erişildi.

Smith, R. (2018). The Dutch have the best work-life balance. here's why . https:/www.weforum.org/agenda/2018/02/the-dutch-have-the-bestwork-life-balance-here-s-why/ adresinden 14.12.2018 tarihinde erişildi.

Working Families (2017).What do today's working fathers want on father's day? https://www.workingfamilies.org.uk/news/fathers-day/ adresinden 04.06.2018 tarihinde erişildi.

\section{Kaynakça Bilgisi / Citation Information}

Özçelik-Kaynak, K. ve Öztuna, B. (2019). Erkeklerde iş-yaşam dengesi üzerine bir araştırma. OPUS-Uluslararası Toplum Araştırmaları Dergisi , 10(17), 859-876. DOI: 10.26466/opus.522715 